\title{
FACTORS INFLUENCING TRUST IN REMOTE TEAMS
}

\author{
Cristina VEITH $^{a^{*}}$, Iyad ISBAITA $^{b}$, Paul MARINESCU $^{c}$ \\ ${ }^{a, b}$ Bucharest University of Economic Studies, Romania \\ ${ }^{c}$ University of Bucharest, Romania
}

\begin{abstract}
For the research we chose to analyze remote teams and the factors that influence trust in conducting professional activities remotely, due to the fact that in the current context this type of activity is much more widespread than we imagined three years ago. We have tried to understand how trust in remote work can be influenced in order to avoid possible problems caused by ignorance. For managers as well as for members of remote teams, establishing relationships based on trust has been and continues to be a challenge at the moment. The present study wants to highlight which are the main groups of factors that we must consider regarding the relationship with the element of trust in the context of conducting remote work. For the empirical data collection, we used a questionnaire. The data were analyzed with SPSS factorial analysis. The results obtained in the analysis of the factors show us that in our country, at present, there are no significant differences between the aspects considered important from the perspective of the remote team leader compared to the simple members. The nine factors were grouped into two components both for remote team leaders and for their simple members. For organizations operating in a remote system, it is important to remember the two defining components, in order to act accordingly when faced with productivity issues or adaptation to the new work system.
\end{abstract}

KEYWORDS: Covid-19 pandemic, remote team leader, remote teams, trust.

\section{DOI: $10.24818 / \mathrm{IMC} / 2021 / 05.04$}

\section{INTRODUCTION}

The pandemic has accelerated digitalization in many areas of activity. Many people started working from home, this being the only possibility during the state of emergency in order to be able to continue working. The transition from the classic way of working to a remote system, as well as digitalization in general, are implemented by the decisions taken by management based on factors from the internal or external environment of the organization (Zawakcki-Richter \& Latchem, 2018). The stress caused by both the pandemic and the changes, that it brings with it, leads to an increase in anxiety and a diminishing to trust. This presupposes correct leadership (Ross, 2021). Managers need to set clear goals and eliminate the state of insecurity and pointless discussions within their teams. Trust can be explained here by three main elements: "integrity, ability, and benevolence, which means that a trustworthy team member is honest, capable, and caring" (Kildiushova, 2021). According to Larzelere \& Huston trust is defined as "the extent that a person believes another person (or persons) to be benevolent and honest" (Larzelere \& Huston, 1980).

Today we ask ourselves whether it is possible to return to the situation before the pandemic, when the vast majority worked from office spaces. Remote work is not a new element. These possibilities have existed and have been used by some organizations for the last 20 years (Caligiuri et al., 2020). However, technology has advanced a lot and each individual has learned to use the Internet and tools such as a laptop, tablet or smartphone. Digitalization is a part of everyone's daily life, which has demonstrated its advantages and disadvantages even before the pandemic. Studies, related to the

\footnotetext{
* Corresponding author. E-mail address: cristina.veith@fabiz.ase.ro
} 
jobs of the future and the changes that technology brings in this direction, can be found in a large number of academic literature. An important aspect related to the effects of digitalization on the development of distance professional activity is the skills that employees must have to maintain their long-term position (Rump \& Eilers, 2020). In Germany, for example, some universities offer solutions such as professional retraining and new specializations to acquire the skills and abilities required by the professions of the future (Fritsche \& Harms, 2020).

The main challenge they have faced lately has been related to the workforce and the possibilities to adapt to the new conditions. In order to overcome the crisis, the managers were put in the situation of looking for strategic talents to support the teams for the transition to the new way of working. The existing human resource in most organizations had not been prepared for the challenges posed by the pandemic (Caligiuri et al., 2020). Now that the transition has been implemented, organizations are preparing to adopt a type of remote work-specific culture to maintain the safety and well-being of the workforce (Goasduff, 2020). Of course, it should be noted that not in all branches of the industry and professional activity in general, a total transition to distance activity is possible. In some cases, even if the possibility exists, the results obtained from an exclusive remote activity are not the desired ones. However, almost without exception, organizations had to adapt to new conditions in order to cope in the current market (Butler, 2020).

\section{LITERATURE REVIEW}

Some organizations have taken the first steps toward digitalization for several years now. These organizations believed that by using modern technologies they can provide a better customer experience and a better satisfaction of their needs. Another advantage that digitalization offers is the possibility to monitor the customer experience and offer loyalty programs (Darryl, 2018). For example, the German restaurant "Byte-Burger" (Gehring et al., 2017). We presented this example because one of the industries most affected by the pandemic was that of tourism and gastronomy.

Digitalization of value flows within organizations and can increase productivity, but requires them to ensure the exchange of information both horizontally and vertically and to decentralize the decision-making process (Hermann, Pentek, \& Otto, 2016). Digitalization, increasing the importance of digital platforms and data stored in the virtual environment, also brings risks to their security (Kagermann et al., 2016).

The new technologies, to which others are constantly being added, require the creation of very clear and well-documented structures and methodologies. They impact most economic branches from energy, health services, but also industry and infrastructure in general (Santosa et al., 2017).

A few years ago, working from home was also called smart working. It could take place both in the standard spaces arranged within the companies, but also in virtual workspaces. Companies knew that this new type of work involves introducing new elements into the culture of the organization, which are related to the responsibilities of each employee to the objectives of the organization, the results obtained, the trust on which the activity is based, changing forms and methods of control, but also on elements such as empathy or management style different from those previously practiced. Smart working also involves accepting a dose of flexibility in terms of working time and location of professional activity (Menshikova, 2020).

The work carried out in remote teams is much more demanding and stressful due to the fact that we cannot observe the reactions of bosses and colleagues directly (Morrison-Smith \& Ruiz, 2020). The human brain needs direct interaction, observation of gestures and body language, which are lost online. At present, stress is also caused by the insecurity and fear caused by possible infection with the Covid-19 virus. All over the world there is a concern to find solutions to reduce the stress that exists in people's professional lives at the moment. An example is the one applied in Dubai after the outbreak of the pandemic and which refers to general measures for the transfer of professional activity in a remote system for everyone or the granting of paid leave for situations where remote 
work was not possible or the leave without pay without losing their jobs or temporarily reducing their wages (Haak-Saheem, 2020).

The transition to remote work is a challenge for both management and team members. People are prone to trust each other, even if there are people who say they only believe in those who have shown that they deserve our trust. This inclination of human beings is demonstrated by many studies and situations in which it has been proven that for many years we have been deceived by some people who did not deserve the trust given. On the other hand, people are inclined towards reciprocity. When someone does us a favor, we try to reward them. This also happens in professional life. When the organization gives us flexibility and autonomy, in general, we reward it with an effort extra effort in performing our duties. Reciprocity is an important element on the road to building trust. Investing in fair and solid interpersonal relationships tends to bring us greater benefits over time. Also, people who are trustworthy are those who have the ability to establish relationships of trust more easily (Brower, 2020). Thus, in order to gain trust in a team, we must keep in mind that its members must know each other and share interesting and fun aspects of their lives. In general, conversations in remote teams are planned and oriented towards solving professional problems. In order to gain trust, we need to show empathy and create easy spaces for conversation in which remote team members get to know each other (Retrium Team, 2021).

Regardless of the environment in which we operate, it is necessary to gain and give trust. By sharing opinions and ideas, through open discussions, we manage to combat communication problems and increase productivity in an environment each team member gives and receives support from colleagues (Sinha, 2021). As a manager we must avoid making too many mistakes, as this could create confusion and mistrust among team members (Sandman \& Lanard, 2020).

Remote work has put pressure on teams and friendships, which is why some companies have started to organize coffee breaks, welcome actions, meetings for informal information exchanges in the virtual environment using online applications and tools (Goasduff, 2020).

People tend to believe in the things they see, which is why in the virtual environment some managers are not aware of the effort made by team members because they do not see them when they work (Ross, 2021). The Gartner study points out that in organizations where the level of trust is high, it demonstrates an involvement 76 percent higher than in the case of organizations with a low level of trust. Thus, management must ensure a sense of mutual trust for remote teams to succeed (Goasduff, 2020).

Successful teams are formed by the successful development of teamwork, and for this, trust is an essential element. As a manager, we must give and show the trust we have in our colleagues both by expressing them and by clear actions (Sinha, 2021).

When team members feel insecure, their level of productivity decreases, as does their ability to perform their tasks. In addition, the availability and ability to think freely is limited. This does not mean that the person does not have the necessary skills to fulfill the responsibilities, but that his emotional state of concern does not allow him to reach the desired level of performance. Individuals are willing to consume energy within teams when they trust and not in a situation where they have feelings of insecurity and uncertainty (Ross, 2021).

Many of the current problems within organizations are due to the lack of management experience and their lack of trust in the possibility of achieving the desired results in remote work. This type of thinking has so far blocked the development of this way of working. We must all learn that it does not matter when and where the professional activity is carried out, but only the results are relevant. In remote work, everyone needs to trust their teammates both emotionally and rationally. Rational trust is based on the fact that it recognizes the abilities of colleagues, but this is not enough for the success of a team working remotely. Emotional trust requires empathy and closeness and understanding for the rest of the team. Members of a remote team must learn to trust each other regardless of the role they play in the team (Retrium Team, 2021). The head of a remote team is not allowed to get involved in micromanagement activities because it will send a message of distrust to 
the work done by his teammates (Ross, 2021). In remote teams, the manager must take time for one-on-one discussions before any other activity. Openness to team members and their problems ensures a state of balance and trust in remote work. A number of managers forget to be with their team members, which leads to loss of trust and decreased team efficiency (Rice, 2021).

The motivation and commitment of today's employees is very different from that of 20 or 30 years ago. The academic literature speaks of four important phases that employees' expectations have gone through since 1900 and until today. For the talent they show and the performance with which they contribute to the development of the organization, current employees expect to enhance their creativity, to establish a better balance between professional and private life and to find a superior meaning for the work carried out (Turner, 2020).

For the proper conduct of remote work, all team members need certain digital skills. However, the skills needed for employees in the future are not limited to digital skills and the ability to decide to lead a team, to work to support colleagues, to interact and to present and support a topic with arguments. The members of a remote team must show creativity, ability to conceptualize and entrepreneurial spirit (Okros, 2020). All these skills are all the more important for managers, who today are put in a position to motivate the people they lead remotely. The manager who fails to understand and adapt to the demands of remote work will create tension and stress within the team (Yi-Lin Forrest et al., 2020). The manager of a remote team is not allowed to express ambiguity. All his statements and topics addressed must be in line with reality, have a unique source of origin, be expressed clearly and especially accurately (Koh, 2020). In addition, managers must consider giving few goals on a regular basis, pursuing them and assuring team members that their work is appreciated and safe, and that the organization has taken all necessary measures to maintain the health of employees (Mendy et al., 2020).

In order to cope with remote work, many organizations have had to implement new technologies and use online platforms that allow this type of activity. For their use, trainings and specializations were necessary for all those involved. In the first phase, all the organizations resorted to emergency solutions, after which, in the second phase, they implemented schooling and the improvement necessary for the use of new tools (PWC, 2020).

Despite all the challenges of working remotely, a studio in the Czech Republic shows that five out of 10 employees do not want to return to the office. There is a perception on the part of some organizations that remote work blocks the possibilities for collaboration and leads to lower productivity, which means higher costs and loss of profit for them. To date, no study or statistics confirm this perception (Hickman, 2020). On the other hand, more and more people work in hybrid teams, having colleagues from all over the world with whom they may not meet too soon (Sinha, 2021).

\section{RESEACH METHODOLOGY}

For our research we chose to talk about remote teams and the factors that influence trust in conducting professional activities remotely, due to the fact that in the current context this type of activity is much more widespread than we imagined three years ago. We have tried to understand how trust in remote work can be influenced in order to avoid possible problems caused by ignorance. For managers as well as for members of remote teams, establishing relationships based on trust has been and continues to be a challenge at the moment. The difference from the situation in which the professional activity took place in the companies' headquarters is that each member of the team, regardless of the position they occupy, must share their time and responsibilities without being able to rely on direct interaction with their colleagues. Managers question that remotely the possibilities to control the extent to which everyone performs their tasks responsibly is more difficult, or, from the perspective of some, even impossible. On the other hand, the team members have the feeling that the effort they make in carrying out the work tasks is not noticeable. For all 
those involved, this new situation involves a process of adaptation and learning to cope well with the new context. The present study wants to highlight which are the main groups of factors that we must consider regarding the relationship with the element of trust in the context of conducting remote work.

The real costs and possibilities of data collection in the context of the current pandemic have turned our attention to choosing a quantitative research method. The large number of factors influencing trust made us choose the factor analysis. Factorial data analysis is a method of quantitative research. The objective for which we used this tool is to transform numerical data tables, resulting from descriptive statistical analysis, into graphs, easy to interpret. The grouping of the different factors in defining components made us understand which are the main aspects through which we can influence trust in the sense of ensuring the achievement of objectives proposed by each organization when the activity takes place in remote work. When the group of factors compared is too large, the complexity of the situation makes it difficult to choose the clearest way in which different factors correlate with each other. We chose this technique as the most appropriate to highlight groups of factors that behave similarly.

Factor analysis is used to solve two types of problems: reducing the number of variables to increase the speed of data processing and identifying hidden patterns in the relationships between data. Factor analysis refers to a wide range of statistical techniques used to represent a set of variables in accordance with a small number of hypothetical variables, called factors. This type of analysis is used extensively in various fields, such as: psychology, social sciences, production management, operational research, development, etc. Some of the software packages dedicated to this type of analysis are: Statistics, SAS, SPSS (Cărbureanu, 2010).

In order to obtain a more complete picture, we addressed a diverse number of employees from the perspective of age, professional experience, gender, the environment of the professional activity, the role in the company and the position within the remote teams. To perform the analysis, we used a questionnaire answered by 439 people. Of these, only 410 were introduced in the analysis because 29 of the respondents did not have a conclusive experience in remote work. Of the 410 respondents, 246 were women, 172 people coordinated remote teams, 78 of them are managers, 287 work in urban areas and 246 people have over three years of experience in their professional activity.

In the analysis of the factors, 9 correlated variables and a classification variable were taken into account. The classification variable was the one that indicated whether the person had the role of team leader or simple member of the remote team. In the questionnaire, the respondents chose the classification factors of their actual status, and for the rest of the factors a Likert ranking scale with seven answer variants was used. Thus, the respondents chose on a scale from 1 to 7 the hierarchical level that they considered the most appropriate for each question. Respondents were asked to what extent certain factors influence their trust in working in remote teams. Thus, nine factors were extracted that were evaluated by the respondents compared to the element of trust in the work performed in the remote system.

The first question we sought to answer in this research was the possible differences between the factors that would form the components resulting from the use of factor analysis.

The second question concerns the possible difference in the extent to which the nine factors divided into components based on factor analysis will explain to a greater or lesser extent the variance for the group of team leaders compared to the group of simple remote team members. Thus, the following two research hypotheses were formulated:

H1: The factors included in the main components will not differ from the perspective of team leaders, compared to that of simple members of a remote team;

$\mathrm{H} 2$ : The variance explained by the main components will be different for team leaders compared to simple remote team members. 


\section{RESULT AND DISCUSSION}

For the factor analysis, nine factors were chosen from the questionnaire that were grouped in two sets of tests according to the classification variable called the position within the remote team. Thus, the factor analysis was performed initially for those who were team leaders and in the second phase for those who had only the role of members in the remote team.

In both phases we started by using the factor analysis validity test, called KMO and Bartlett's Test. According to the data presented in table one, we notice that the conditions imposed by the factorial analysis are met. The number of people who joined the group of team leaders was sufficient to be able to obtain a result of 0.745 for the indicator related to the size of the sample of respondents. The values obtained further in the Bartlett's sphericity test were also very good, the result obtained having an error probability of less than 0.001 .

Table 1. KMO and Bartlett's Test

\begin{tabular}{|c|c|c|}
\hline Kaiser-Meyer-Olkin Measure of Sampling Adequacy. &, 745 \\
\hline Bartlett's Test of Sphericity & Approx. Chi-Square & 603,965 \\
\cline { 2 - 3 } & df & 36 \\
\cline { 2 - 3 } & Sig. &, 000 \\
\hline
\end{tabular}

Source: own research - spss result for cases for team leaders $=1$

In Table 2 we present the variance for the first two components which explains just under 58 percent of the influence of the 9 factors analyzed on the classification variable.

Table 2. Total Variance Explained for team leaders

\begin{tabular}{|c|c|c|c|c|c|c|c|c|c|}
\hline \multirow[b]{2}{*}{$\begin{array}{c}\text { Compo- } \\
\text { nent }\end{array}$} & \multicolumn{3}{|c|}{ Initial Eigenvalues } & \multicolumn{3}{|c|}{$\begin{array}{l}\text { Extraction Sums of } \\
\text { Squared Loadings }\end{array}$} & \multicolumn{3}{|c|}{$\begin{array}{l}\text { Rotation Sums of } \\
\text { Squared Loadings }\end{array}$} \\
\hline & Total & $\begin{array}{c}\% \text { of } \\
\text { Varian- } \\
\text { ce }\end{array}$ & $\begin{array}{c}\text { Cumu- } \\
\text { lative } \\
\%\end{array}$ & Total & $\begin{array}{c}\% \text { of } \\
\text { Varian- } \\
\text { ce }\end{array}$ & $\begin{array}{c}\text { Cumu- } \\
\text { lative } \\
\% \\
\end{array}$ & Total & $\begin{array}{c}\% \text { of } \\
\text { Varian- } \\
\text { ce }\end{array}$ & $\begin{array}{c}\text { Cumu- } \\
\text { lative } \\
\% \\
\end{array}$ \\
\hline 1 & 3,767 & 41,861 & 41,861 & 3,767 & 41,861 & 41,861 & 2,985 & 33,172 & 33,172 \\
\hline 2 & 1,431 & 15,897 & 57,758 & 1,431 & 15,897 & 57,758 & 2,213 & 24,586 & 57,758 \\
\hline 3 & ,984 & 10,938 & 68,696 & & & & & & \\
\hline 4 & ,882 & 9,802 & 78,499 & & & & & & \\
\hline 5 & 678 & 7,534 & 86,033 & & & & & & \\
\hline 6 & ,402 & 4,462 & 90,495 & & & & & & \\
\hline 7 & ,346 & 3,844 & 94,339 & & & & & & \\
\hline 8 & ,316 & 3,510 & 97,849 & & & & & & \\
\hline 9 & ,194 & 2,151 & 100,000 & & & & & & \\
\hline
\end{tabular}

Source: own research - spss result for cases for which Level of change goal achievement $=1$

A total of 9 components resulted in which the 9 analyzed factors were grouped. From figure 1, the analysis of the main components, we notice that the first two components are the most important, but that they explain just under $58 \%$ of the result obtained. The first two components were chosen respecting the condition that Eigenvalue be over 1. 


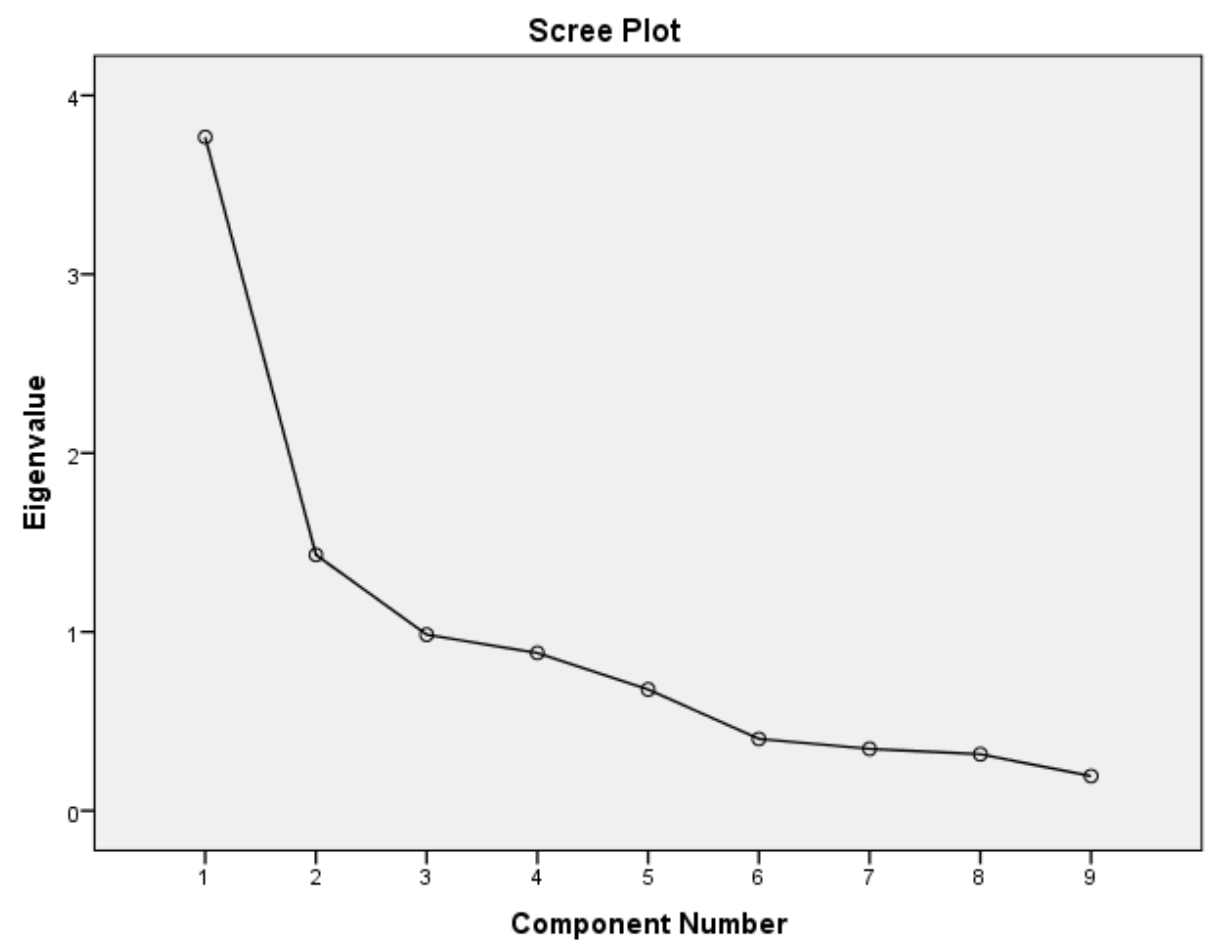

Figure 1. Principal Component Analysis spss plot result for team leader answers = 1 Source: own research - spss

In the next stage, the most important factors that make up each component were analyzed. Thus, we notice that the number one component is determined by factors such as: supportive or authoritarian management style, involvement in the activity, high digital skills, assertiveness of communication and empathy shown to team members. Out of a total of 9 factors, six define the component. Component one includes factors that we include in the group called the work team and these features. The next component includes factors related to technology, remote work trust and the possibility it offers as a stimulus for creativity. We call the second component, based on the invoices it contains, the technology and the work of the future.

Table 3. Component matrix

\begin{tabular}{|l|c|c|}
\hline \multirow{2}{*}{} & \multicolumn{2}{|c|}{ Component } \\
\cline { 2 - 3 } & 1 & 2 \\
\hline supportiv management stil &, 802 & \\
\hline involvement &, 797 & \\
\hline digital skills &, 790 & \\
\hline empathy &, 628 & \\
\hline authoritarian management stil &, 555 & \\
\hline assertiveness &, 551 & \\
\hline remote work in future & &,- 836 \\
\hline trust in remote work & &, 816 \\
\hline $\begin{array}{l}\text { creativity is stimulated by } \\
\text { technology }\end{array}$ & &, 608 \\
\hline
\end{tabular}

Source: own research - spss

In Table 4 we present the results of the KMO and Bartlett's test for respondents who were only simple members of the remote teams. And for this situation it is demonstrated that the number of 
respondents was sufficient to obtain a very good result in the factor analysis. The sphericity test also presents results that would encourage the development of the analysis for this second group of respondents as well. Comparing the results, we easily notice that the higher number of respondents who were just simple members of a remote team led to better results in the test presented in Table 4 . And, in this case, confirms the hypothesis that, for the correct conduct of a factor analysis, a number of respondents greater than 150 people is required.

Table 4. KMO and Bartlett's Test

\begin{tabular}{|c|c|c|}
\hline Kaiser-Meyer-Olkin Measure of Sampling Adequacy. &, 846 \\
\hline Bartlett's Test of Sphericity & Approx. Chi-Square & 1375,109 \\
\cline { 2 - 3 } & df & 36 \\
\cline { 2 - 3 } & Sig. &, 000 \\
\hline
\end{tabular}

Source: own research - spss result for cases for team members $=2$

In Table 5 we present the variance for the first two components, which explains over 70 percent of the variance of the 9 factors for the classification factor: members of a remote team. From the obtained results we notice that the first component explains over 51 percent of the variant of the factors.

Table 5. Total Variance Explained for team members

\begin{tabular}{|c|c|c|c|c|c|c|c|c|c|}
\hline \multirow{2}{*}{$\begin{array}{c}\text { Co } \\
\text { mpo } \\
\text { nent }\end{array}$} & \multicolumn{3}{|c|}{ Initial Eigenvalues } & \multicolumn{3}{c|}{$\begin{array}{c}\text { Extraction Sums of } \\
\text { Squared Loadings }\end{array}$} & \multicolumn{2}{c|}{$\begin{array}{c}\text { Rotation Sums of Squared } \\
\text { Loadings }\end{array}$} \\
\cline { 2 - 11 } & Total & $\begin{array}{c}\text { \% of } \\
\text { Varian- } \\
\text { ce }\end{array}$ & $\begin{array}{c}\text { Cumu- } \\
\text { lative \% }\end{array}$ & Total & $\begin{array}{c}\text { \% of } \\
\text { Varian- } \\
\text { ce }\end{array}$ & $\begin{array}{c}\text { Cumu- } \\
\text { lative } \\
\text { \% }\end{array}$ & Total & $\begin{array}{c}\text { \% of } \\
\text { Varian- } \\
\text { ce }\end{array}$ & $\begin{array}{c}\text { Cumu- } \\
\text { lative \% }\end{array}$ \\
\hline 2 & 1,652 & 51,690 & 51,690 & 4,652 & 51,690 & 51,690 & 4,220 & 46,883 & 46,883 \\
\hline 3 &, 823 & 9,143 & 79,201 & & & & & & \\
\hline 4 &, 628 & 6,978 & 86,179 & & & & & & \\
\hline 5 &, 412 & 4,580 & 90,759 & & & & & & \\
\hline 6 &, 279 & 3,095 & 93,854 & & & & & & \\
\hline 7 &, 223 & 2,474 & 96,328 & & & & & & \\
\hline 8 &, 182 & 2,020 & 98,348 & & & & & & \\
\hline 9 &, 149 & 1,652 & 100,000 & & & & & & \\
\hline
\end{tabular}

Source: own research - spss result for cases for team members $=2$

Figure 2. shows a considerable difference between the variance expressed by component number one and that expressed by the rest of the components. As in case 1 (team leaders), the factor analysis determined in case two (simple team members) two main components. The remaining three to nine components have an Eigenvalue below 1. 


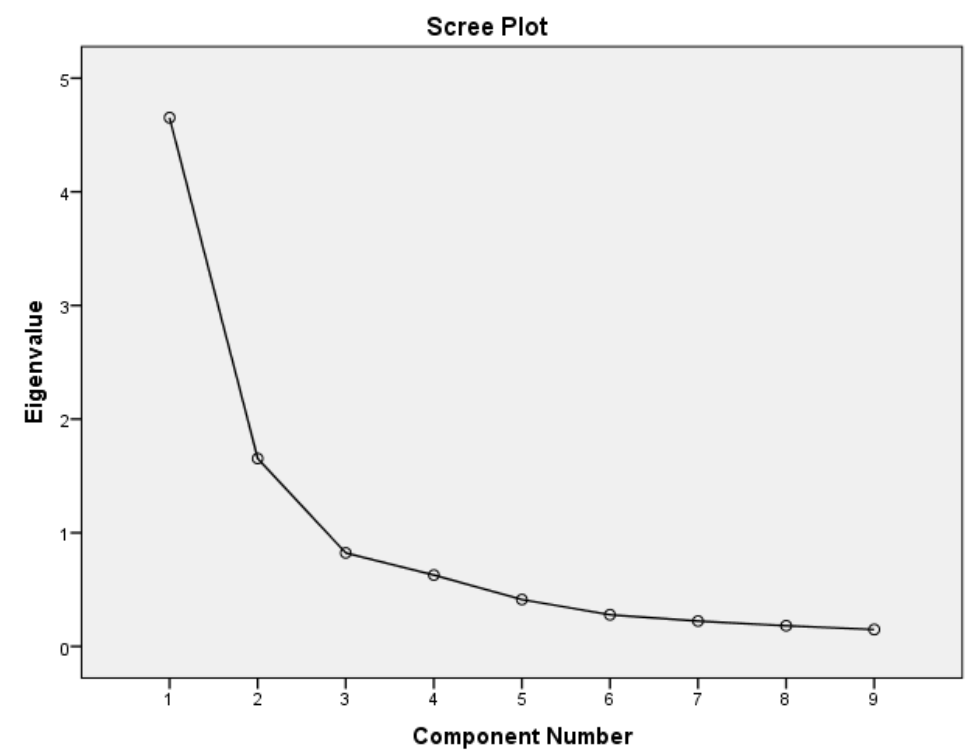

Figure 2. Principal Component Analysis spss plot result for team members $=2$

Source: own research - spss

The main factors that describe both component number one and component number two are in the second case, team members, identical to those presented earlier in the case of team leaders. The order and importance given by the team members to the factors that make up the two components differs slightly from that previously presented in the case of team leaders. However, these differences are not large enough to draw a relevant conclusion. However, one aspect must be kept in mind in relation to the factor called creativity stimulated by technology, namely that it is found in the case of team members with an almost equal share in both component one and component two. Thus, for some respondents, acting as simple members of remote teams, creativity is an element that falls into component one, which describes the work team and its features. For the other side of respondents, as members of remote teams, creativity is about technology and the work of the future as well as the responses received from remote team leaders.

Table 6. Component matrix

\begin{tabular}{|l|r|r|}
\hline \multirow{2}{*}{} & \multicolumn{2}{|c|}{ Component } \\
\cline { 2 - 3 } & 1 & 2 \\
\hline involvement &, 903 & \\
\hline empathy &, 875 & \\
\hline digital skills &, 873 & \\
\hline supportiv management stil &, 824 & \\
\hline assertiveness &, 814 & \\
\hline authoritarian management stil &, 523 & \\
\hline $\begin{array}{l}\text { creativity is stimulated by } \\
\text { technology }\end{array}$ &, 498 &, 465 \\
\hline trust in remote work & &, 933 \\
\hline remote work in future & &,- 927 \\
\hline \multicolumn{2}{|c|}{ Source: own research - spss } \\
\hline
\end{tabular}

Comparing the results obtained in the two cases, namely team leader and remote teams, we notice that in remote teams, the differences between team leaders and their members are smaller than in 
the case of classic teams. The grouping of factors into two almost identical components for the two analyzed perspectives demonstrates that working in a remote system levels the differences imposed by a traditional hierarchical system. The order of the factors that composed the second component is the same in both cases analyzed. Regarding the number one component, we notice that we have small differences in the hierarchy of defining factors, namely, for team leaders the aspect related to the support they provide was presented as the main factor followed by the involvement of all team members in solving organizational objectives. From the perspective of the team members, the involvement was placed in the first place. Digital skills and empathy for team members were in both cases in third and fourth place and vice versa. If for the team leaders the digital skills were a little more important, they were immediately followed by empathy that is on the third place in the ranking of the factors that make up the number one component from the perspective of the team members. Thus, we can say that the $\mathrm{H} 1$ hypothesis is partially demonstrated, because the differences resulting from the analysis of the two perspectives are not important. Regarding the H2 hypothesis, we can say that this is demonstrated, because the difference between the cumulative variance of the two components in the case of team leaders is smaller than that explained by the nine factors in the case of simple members of remote teams.

\section{CONCLUSIONS}

The main issues addressed in this article relate to the challenges posed by the crisis due to the COVID-19 pandemic and thus the digitalization of professional life. The research highlighted the importance of trust for the proper conduct of professional activities in remote work.

The main factors influencing the trust and implicitly the good development of the activity within the remote team were selected and included in the questionnaire to research the particular situation in our country.

We found in the academic literature that, between the leaders of the remote teams and their members, there were differences in approach in many organizations. The results obtained in the analysis of the factors show us that in our country, at present, there are no significant differences between the aspects considered important from the perspective of the remote team leader compared to the simple members.

The nine factors were grouped into two components both for remote team leaders and for their simple members.

The main resulting difference refers to the creativity factor which, in the case of simple members of a remote team, could not be clearly included in one of the two components, being found with a similar value in both.

The factors taken into account in the present analysis, and grouped by means of the analysis of the factors in two components, did not lead to the total explanation of the variance. Another difference resulting from the analysis performed, refers to the share in which the two cumulated components explain the variance. The lower share explained in the case of remote team leaders shows us, that from their perspective, there are other relevant factors that have been omitted by this research. The share of over 70 percent obtained in the case of simple team members shows us that the analyzed factors covered the influence on trust better than in the case of remote team leaders. This is a limitation of the present research, which in the future can be extended by involving several factors in the analysis.

For organizations operating in a remote system, it is important to remember the two defining components, in order to act accordingly when faced with productivity issues or adaptation to the new work system. Thus, the purpose of the present paper is to present the results obtained through empirical study, in order to learn and apply the best solutions in practice. The challenges that managers face in coordinating remote teams will not go away without all the necessary measures being taken. 
Remote work will continue to grow, even after overcoming the crisis caused by the Covid-19 pandemic. To avoid the disadvantages of remote work, organizations are adopting hybrid business systems. Many employees do not want to give up the flexibility and autonomy offered by remote work, but they want to have the opportunity to periodically socialize with their colleagues. In order not to lose their employees, the organizations are preparing to offer the possibility to carry out the activity in a hybrid system, offering the possibility to the employees to choose where they want to work. In order to choose the best solutions, the organizations turn to consulting companies and training solutions for employees.

\section{ACKNOWLEDGMENT}

This paper is a result of the research conducted by the authors in the last 8 months and carried out within the doctoral program of the Management Doctoral School - Bucharest University of Economic Studies. We would like to express our sincere thanks to the respondents to our questionnaire, who made it possible to conduct this study.

\section{REFERENCES}

Brower, T. (2020, September 20). Working Remote: How To Build Trust From A Distance. Retrieved from FORBES: https://www.forbes.com/sites/tracybrower/2020/09/20/ workingremote-how-to-build-trust-from-a-distance/?sh $=307 \mathrm{e} 789 \mathrm{c} 271 \mathrm{e}$

Butler, L. (2020). Business as usual? Welche Veränderungen setzen sich auch nach der Krise im Arbeitsalltag durch? Wirtschaftsinformatik \& Management, 1-3.

Caligiuri, P., De Cieri, H., Minbaeva, D., Verbeke, A. \& Zimmermann, Z. (2020). International HRM insights for navigating the COVID-19 pandemic: Implications for future research and practice. Journal of International Business Studies, 697-713.

Cărbureanu, M. (2010). A FACTOR ANALYSIS METHOD APPLIED IN DEVELOPMENT FIELD. Analele Universităţii "Constantin Brâncuşi”, 1, 187-194.

Darryl, B. (2018). The Future of Food: The Internet of Things and the Connected Restaurant Kitchen. Providence: Upserve, Inc.

Fritsche, J. Ph. \& Harms, P. Ch. (2020). Corona-Krise: (Wirtschafts-)politische Perspektiven. ZBW Leibniz-Informationszentrum Wirtschaft, 266-271.

Gehring, M. et al. (2017). Digitalisierung in Schweizer Klein- und Mittelunternehmen. Sankt Gallen: FSH St. Gallen.

Goasduff, L. (2020, July 30). The Leader Checklist to Foster Trust on Remote Teams. Retrieved from GARTNER: https://www.gartner.com/smarterwithgartner/the-leader-checklist-to-fostertrust-on-remote-teams

Haak-Saheem, W. (2020). Talent management in Covid-19 crisis: how Dubai manages and sustains its global talent pool. Asian Business \& Management, 298-301.

Hermann, M., Pentek, T. \& Otto, B. (2016). Design principles for industrie 4.0 scenarios. Koloa, HI, USA: 49th Hawaii International Conference on System Sciences (HICSS), IEEE.

Hickman, A. (2020, August 12). How to Build Trust and Boost Productivity Within Remote Teams. Retrieved from Gallup: https://www.gallup.com/workplace/316931/build-trust-boostproductivity-within-remote-teams.aspx

Kagermann, H., Anderl, R., Gausmeier, J., Schuh, G. \& Wahlster, W. (2016). Industrie 4.0 in a Global Context: strategies for cooperating with international partners. Munich: Herbert Utz Verlag.

Kildiushova, T. (2021). Building trust in virtual teams. Johannes Kepler Universität. Preluat de pe https://epub.jku.at/obvulihs/content/titleinfo/6021967 
Koh, J.-J. (2020, April 1). Simple and Effective Workplace Communications During COVID-19. Retrieved from Vermilion Pinstripes: https://www.vermilionpinstripes.com/ communications/simple-and-effective-workplace-communications-during-covid-19

Larzelere, R. E. \& Huston, T. L. (1980). The Dyadic Trust Scale: Toward understanding interpersonal trust in close relationships. Journal of Marriage and the Family, 42(3), 595-604. https://doi.org/10.2307/351903.

Mendy, A., Stewart, M. L. \& Van Akin, K. (2020, April 17). McKinsey \& Company. Retrieved from McKinsey \& Company Business Functions: https://www.mckinsey.com/businessfunctions/organization/our-insights/a-leaders-guide-communicating-with-teams-stakeholdersand-communities-during-covid-19\#

Menshikova, M. F. (2020). Introducing Smart-Working in the Conditions of Digital Business Transformation: Analysis of an Employee's Experience. (S. Gabler, Ed.) Die vierte Dimension der Digitalisierung, 59-72.

Morrison-Smith, S. \& Ruiz, J. (2020). Challenges and barriers in virtual teams: a literature review. SN Applied Sciences, 2:1096. Preluat de pe https://doi.org/10.1007/s42452-020-2801-5.

Okros, A. (2020). Harnessing the Potential of Digital Post-Millennials in the Future Workplace. Cham: Springer Nature.

PWC (2020, March 27). Effective operational communications in times of crisis with Beekeeper. Berlin: PWC. Retrieved from www.pwc.de: https://www.pwc.de/de/covid-19/covid-19effective-operational-communications-in-times-of-crisis.pdf

Retrium Team. (2021, April 30). How To Develop Trust Within A Remote Team Through Constant Communication. Retrieved from RETRIUM: https://www.retrium.com/blog/develop-trustwithin-remote-team-through-communication

Rice, D. (2021, April 26). Meeting the Challenge of Building Trust with Remote Teams. Retrieved from hrexchangenetwork.com: https://www.hrexchangenetwork.com/employeeengagement/articles/meeting-the-challenge-of-building-trust-with-remote-teams

Ross, M.-C. (2021, February 01). Six Critical Steps to Building Trust in Remote Teams. Retrieved from THE CEO INSTITUTE - A meeting of minds: https://www.ceoinstitute.com/ memberexperience/ceo-insight/blog-article/six-critical-steps-to-building-trust-in-remote-teams

Rump, J. \& Eilers, S. (2020). Die vierte Dimension der Digitalisierung. Berlin: Springer Gabler.

Sandman, P. M. \& Lanard, J. (2020). COVID-19: The CIDRAP Viewpoint. Regents of the University of Minnesota, 1-11.

Santosa, C., Mehrsaia, A., Barrosa, A., Araujob, M. \& Ares, E. (2017). Towards Industry 4.0: an overview of European strategic roadmaps. Vigo: Manufacturing Engineering Society International Conference 2017, MESIC 2017.

Sinha, R. (2021, March 23). New to the Team? Here's How to Build Trust (Remotely). Harvard Business Review. Retrieved from https://hbr.org/2021/03/new-to-the-team-heres-how-to-buildtrust-remotely

Turner, P. (2020). Employee Engagement in Contemporary Organizations. Cham: Springer Nature.

van Fenema, P. C. \& Romme, A. G. L. (2020). Latent organizing for responding to emergencies: foundations for research. Journal of Organization Design, 1-16.

Yi-Lin Forrest, J., Nicholls, J., Schimmel, K. \& Liu, S. (2020). Managerial Decision Making - A Holistic Approach. Cham: Springer. 